A NUMERICAL APPROACH FOR THE ELASTOPLASTIC UNILATERAL CONTACT BETIEEN ADJACENT STRUCTURES DURING EARTHQUAKES

\author{
A. A. LIOLIOS \\ Democritus-Universitv of Thrace, Institute of Struc- \\ tural Mechanics, GR-67100 Xanthi, Greece
}

\begin{abstract}
The paper presents a numerical treatment for the proble of earthquake interaction among neighboring buildings whe unilateral elastoplastic contact under second-order geometr and other instabilizing effects can take place. The method based on formulating the problem by the finite element meth as an inequality one and on solving this by the Houbolt tim discretization scheme and nonlinear mathematical programmin! methods. Some results concerning a two-building system undej P-Delta effects are given in a numerical example.
\end{abstract}

\title{
INTRODUCTION
}

Pounding between adjacent structures has been, as wellknown (see e.g. Refs. 1-3), one of the main usual causes of significant damages in seismically active regions, where the building codes allow partial or full contact among neighboring buildings. Mathematically, the governing conditions of the relevant problem are equalities as well as inequalities. The latter ones concern on the one hand the possibility to be transmitted compressive stresses only (no tension) on the interface, and on the other hand the appearence of retire ment relative displacements (no penetration) for the same interface points, where unilateral contact can take place. So the problem belongs to inequality problems of mechanics, for which a mathematical treatment can be obtained by the variational inequality concept (Ref. 4).

As regards numerical results, some interesting parame - 
tric studies concerning simplified models of single-degreeof-freedom systems have been already reported (Refs. 2,3). These investigations are simplified and based on a trial and-error approach. A more realistic numerical treatment of such inequality problems in earthquake mechanics for multidegree-of-freedom structural systems has been presented in Refs. 5-8.

The aim of the present paper is to deal with a numerical approach to the above outlined dynamic inequality problem when some instabilizing effects are taken into account. The latter concern here P-Delta effects and elastoplastic-softening/fracturing unilateral conditions. The method is based on a double discretization, in space by the finite element method and in time by the Houbolt method, and on solving a nonconvex linear complementarity problem in each time-step. Finally, the proposed approach is applied to a civil-engineering example and some conclusions are discussed.

\section{METHOD OF ANALYSIS}

For simplicity, a system of two adjacent buildings (A) and (B) is considered. The extension to systems with more than two buildings is straightforward, certainly. The case of frictionless unilateral contact is studied here, as the more complicated case of frictional unilateral contact has investigated elsewhere (Refs. 6,8). Due to the assumption of elastoplastic contact, we assume that local impact phaenomena have no significant influence to the global building response.

As in Ref. 5, the system is discretized first in space by the finite element method. Any two associated nodes $i_{A}$ and $i_{B}$ on the interface are considered as connected by $A$ unilateral constraint, normal to the interface. Its stress $r_{i}$, positive when it is compressive, and the corresponding shortening relative displacement $v_{i}$ satisfy the following nonconvex constitutive relation:

$$
r_{i} \in \vartheta R_{i}\left(v_{i}, g_{i}\right)
$$

Here $g_{i}(t)$ is the existing gap at time-moment $t$ between nodes $i_{A}$ and $i_{B}, \vartheta$ is Clarke's generalized gradient and $R_{i}$ is the symbol of nonconvex superpotential (Ref.4). Relation (1) expresses in a general mathematical way the unilateral elastoplastic contact taken into account hardening/softening-fracturing behaviour, unloading/reloading etc. As known, softening/fracturing behaviour corresponds to descending branches in the diagram of (1), and usually has instabilizing effects to numerical procedures. 
For the herein numerical treatment, rel. (1) is piecewise linearized in a way similar to that used by Maier in elastoplasticity (Ref. 9,10$)$. So, by introducing the nonnegative multioliers $w_{i}$, rel. (1) is substituted by the following linear comolementarity conditions:

$$
\begin{array}{rrrr} 
& r_{i}=p_{i} \cdot\left(v_{i}-g_{i}+w_{i}\right)+c_{i} \dot{w}_{i}, & (2 a) \\
w_{i} \geqq 0, & r_{i} \geqq 0, & r_{i} w_{i}=0 . & (2 b, c, d)
\end{array}
$$

Here $c_{j}$ is the damoing coefficient and $p_{i}$ the stress function of the $i-t h$ unilateral constraint. Dots over symbols denote time-derivatives.

Further, the incremental global conditions of dynamic equilibrium for the two buildings (A) and (B) due to a seismic ground displacement history $\underline{x}_{g}(t)$ are written in matrix notation:

$$
\begin{aligned}
& \underline{M}_{A} \Delta \ddot{\underline{u}}_{A}+\underline{C}_{A} \Delta \underline{\dot{u}}_{A}+\left(\underline{K}_{A}+\underline{G}_{A}\right) \Delta \underline{u}_{A}=-\underline{M}_{A} \Delta \ddot{x}_{g}+\Delta \underline{r}, \\
& \underline{M}_{B} \Delta \ddot{\underline{u}}_{B}+\underline{C}_{B} \Delta \underline{\dot{u}}_{B}+\left(\underline{K}_{\underline{D}}+\underline{G}_{B}\right) \Delta \underline{\underline{u}}_{B}=-\underline{M}_{B} \Delta \ddot{\ddot{x}}_{g}-\Delta \underline{\underline{r}} .
\end{aligned}
$$

Here, as usual, $M, \subseteq$ and $\underline{R}$ are the mass, damping and current (tangent) first-ordêr (liñear elastic) stiffness matrices, respectively; $\mathbf{G}$ is the symmetric constant geometric stiffness matrix, depending linearly on preexisting constant stresses (Refs. $10,11,12$ )-through the term Gu alone the geometry changes affect the equilibrium (second-order geometric effects); $\underline{u}(t)$ is the node-displacement vector (relative to ground); $\Delta$ denotes increment; and the coupling term $\underline{r}$ is the vector of interaction forces between (A) and (B) with elements satisfy ing rels. (1)-(2).

Thus the problem consists in computing the time-denendent set $\underline{u}_{A}, \underline{u}_{B}, \underline{r}, \underline{w}$ and $g$ satisfying $(1)-(3)$ for given $\underline{x}_{q}(t)$ and initial conditions. Dūe to inequality conditions, the problem is a nonlinear one even in the case of linear structures. To solve this problem, the step-by-step Houbolt method (Ref.13) is used for the time discretization. So we substitute in (3)

$$
\Delta \underline{\underline{u}}=c_{1} \Delta \underline{u}+\underline{a}, \quad \quad \underline{\underline{u}}=c_{2} \Delta \underline{u}+\underline{b}, \quad(4 a, b)
$$

where $\underline{a}, \underline{b}$ known quantities from previous time-steos and

$$
c_{1}=2 /\left(\Delta t^{2}\right), \quad c_{2}=11 /(6 \Delta t)
$$

the Houbolt method parameters (Ref. 13).

After the above substitution, we arrive eventually to a nonconvex linear complementarity problem of the form (Ref.6)

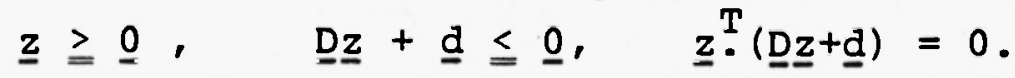


(a)

FRAME (B)

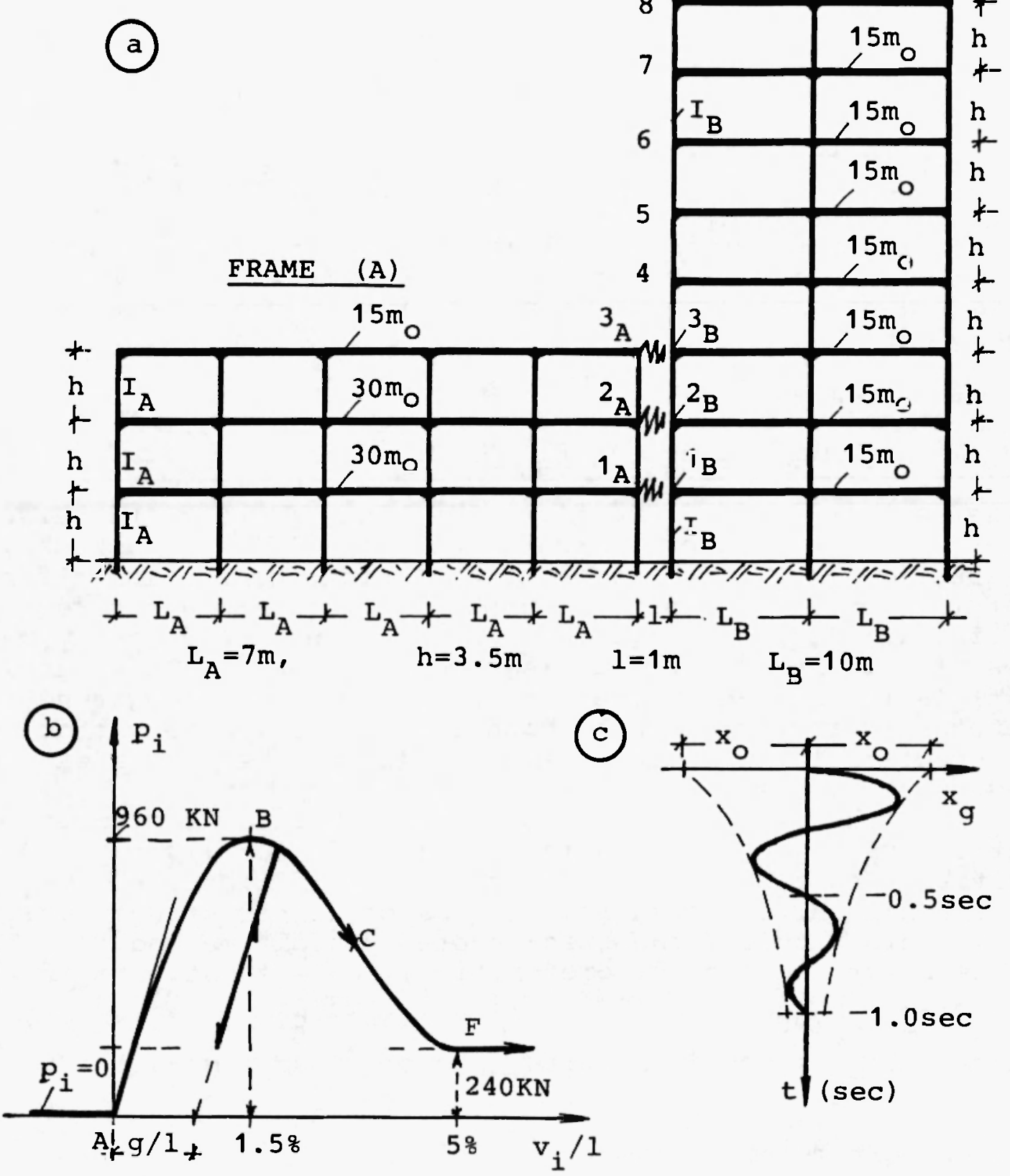

Fig. 1. Numerical example 
This problem is solved by known algorithmes of nonlinear mathematical programming (see e.g. Refs. $4,6,9,10$ ) and thus, in each time-step $\Delta t$, is computed which unilateral constraints are active and which are unactive.

The so-obtained results concern the response of the coupled system, where the unilateral contact and the second-order effects are taken into account. To compare these results with corresponding ones of the uncoupled system, where the interaction effects are not taken into account-as was usual until recently in most aseismic designs- the following influence coefficients are introduced:

$$
\lambda_{i}=\left(Q_{i}^{c}-Q_{i}^{v}\right) .100 / Q_{i}^{u} \text {. }
$$

Here $Q^{\mathrm{u}}$ and $Q^{\mathrm{C}}$ are the absolutely maximum values, which the response quantity $Q$ takes during the whole seismic excitation when the structures are uncoupled and coupled, respectively.

\section{NUMERICAL EXAMPLE}

In the building system of Fig. 1a, the frame (A) is of reinforced concrete with $E_{h}=3.4 * 10^{7} \mathrm{KN} / \mathrm{m}^{2}$ and column-sections $40 / 60$ in $\mathrm{cm}$, and the frame (B) is of steel with $E_{S}=21$ * $10^{7} \mathrm{KN} / \mathrm{m}^{2}$ and columns IPBl 500 . Damping ratio is 58 for (A) and 38 for (B). Both frames have rigid beams with total vertical loads $a_{i} m_{0} g$, where $m_{0} g=98.1 \mathrm{kN}, g=9.81 \mathrm{~m} / \mathrm{sec}^{2}$ and $a_{i}=c 0$ efficients shown in Fig. 1a. Unilateral contact can take place at joint-points $i_{A}, i_{B}$, where $i=1,2,3$. The corresponding to ( $2 a$ ) function $p_{i}$ is assumed to be as shown in Fig. $1 \mathrm{~b}$, where $A B$ and $B C F$ are parabolas of $2-$ nd and $3-r d$ degree, respectively. The above simulation of unilateral contact is certainly a very comolicated task and can be estimated on the basis of experimental results. P-Delta effects for the steel frame (B) are taken into account. The plane system is sub jected to an horizontal earthquake ground displacement

$$
x_{g}(t)=x_{0} e^{-2 t} \sin (4 \pi t), x_{0}=10 \mathrm{~mm},
$$

whose diagram is shown in Fig. 1c. The herein presented approach has been applied in order to estimate quantitatively the interaction effects to seismic response of frames (A) and $(B)$.

From the so-obtained results are shown indicatively in Table 1 only those concerning the storey-shear-forces. The uncoupled stress-state of the three-storey frame (A) is reduced about 168-26\% due to interaction. On the contrary, the uncoubled stress-state of the eight-storey steel frame (B) is increased about 128-118\%. The most remarkable increase is for the 4-th floor of (B), as was expected. So, if 
TABLE 1. Influence coefficients $\lambda_{\text {i }}$ in $(\xi)$ for the storey shear forces of frames (A) and (B)

\begin{tabular}{|c||c|c|c|}
\hline \multirow{2}{*}{ FRAME } & \multicolumn{3}{|c|}{ Storey } \\
& 1 & 2 & 3 \\
\hline (A) & -24.08 & -16.24 & -25.82 \\
(B) & +67.51 & +12.47 & +26.32 \\
\hline
\end{tabular}

\begin{tabular}{|c||c|c|c|cc|}
\hline \multicolumn{1}{|c||}{ FRAME } & 4 & 5 & 6 & 7 & 8 \\
\hline (B) & +117.98 & +47.13 & +46.21 & +42.05 & +45.39 \\
\hline
\end{tabular}

we design the 4-th floor of (B) without taking into account the seismic interaction effects, then the columns of this floor are overstressed about 118\% (more than the designed capacity) - a very remarkable result.

\section{DISCUSSION}

Seismic response of adjacent buildings under second-order geometric and other instabilizing effects can be treated numerically by the herein presented approach. The realization on computer of this procedure can be obtained by available computer codes of the finite element method and nonlinear programming.

As the numerical results of the example show, the in teraction effects may have a considerable influence on the earthquake response of neighbouring buildings with unilateral contact. Therefore, the usual aseismic building design and control without taking into account such a possible interaction under second-order effects may not be realistic. Certainly, the sufficient aseismic joint among buildings is the effective rule for seismically active regions. If this rule is not applicable and if the simulation of interaction can be done in a realistic way (e.g. by experimen tal results), then the seismic joint gap can be adjusted suitably by the herein procedure to control the seismic interaction effects in a desirable level. 


\section{REFERENCES}

1. NEWMARK, N.M. and ROSENBLUETH, E.,"Fundamentals of Earthquake Engineering", Prentice-Hall, Inc., N.J., 1971.

2. WOLF, J.P. and SKRIKERUD, P.E.,"Mutual Pounding of Adjacent Structures during Earthquakes", Nuclear Enging and Design (1980), Vol. 57, 253-275.

3. ANAGNOSTOPOULOS, S.A.,"Pounding of Buildings in Series during Earthquakes", Earthq. Enging and Struct. Dynamics (1988), Vol. 16, 443-456.

4. PANAGIOTOPOULOS, P.D.,"Inequality Problems in Mechanics and Applications. Convex and Nonconvex Energy Functions," Birkhäuser Verlag, Basel-Boston-Stuttgart, 1985.

5. LIOLIOS, A.A.,"A Finite-element Central-difference Approach to the Dynamic Problem of Nonconvex Unilateral Contact between Structures", in: B.SENDOV, R.LAZAROV and P.VASILEVSKI (Eds.), Numerical Methods and Applications, Bulgarian Academy of Sciences, Sofia, pp. 394-401, 1984.

6. LIOLIOS, A.A., "A Linear Complementarity Approach to the Nonconvex Dynamic Problem of Unilateral Contact with Friction between Adjacent Structures", Jnl Appl. Math. Mech. (ZAMM), Vol. 69, No. 5, pp. 420-422, 1989.

7. LIOLIOS, A.A.,"A Numerical Approach to Seismic Interaction between Adjacent Buildings under Hardening or Softening Unilateral Contact" Proc. 9-th Europ. Conf. on Earthq. Enging, Vol. 7-A, pp. 20-25, Moscow, 1990.

8. LIOLIOS, A.A.,"A Numerical Estimation for the Influence of Modifications to Seismic Interaction between adjacent Structures", in: S.A. SAVIDIS (Ed.), Earthquake Resistant Construction and Design, A.A.Balkema, Rotterdam, pp. 461-468, 1991 .

9. MAIER, G.,"Mathematical Programming Methods in Structural Analysis", in: C.BREBBIA and H.TOTTENHAM (Eds.), Variational Methods in Engineering, Southampton University Press, Southampton, pp. 8/1-8/32, 1973.

10. MAIER, G.,"Incremental Elastoplastic Analysis in the Presence of Large Displacements and Physical Instabilizing Effects"; Int. Jnl Sol. Struct. $7,345-372,1971$.

11. CORRADI, L. and DE DONATO, O., "Dynamic Shakedown Theory allowing for Second-order Geometric Effects" Meccanica, Vol. 10, pp. 93-98, 1975.

12. CHEN, W.F. and LUI, E.M., "Structural Stability. Theory 
and Implementation" Elsevier, New York, 1987.

13. BATHE, K.-J. and WILSON, E.L., "Numerical Methods in Finite Element Analysis" Prentice-Hall, Inc., N.J.,1976.

14. ELLER, C., KRÄTZIG, W.B. and BASAR, Y.,"Linear and Nonlinear Stability Analysis of Periodically Excited Visco-elastic Structures", Ruhr-Universität Bochum, Wiss. Mitt. of SFB 151-Tragwerksdynamik, Nr.19, Mai 1991. 